\title{
The Influence of Si/Al Ratio on the Distribution of OH Groups in Zeolites with MWW Topology
}

\author{
Barbara Gil • Bartosz Marszałek • \\ Anna Micek-Ilnicka $\cdot$ Zbigniew Olejniczak
}

Published online: 5 October 2010

(c) The Author(s) 2010. This article is published with open access at Springerlink.com

\begin{abstract}
A series of MWW-type zeolites of increasing $\mathrm{Si} / \mathrm{Al}$ ratio were investigated with respect to their acidic properties. Concentration of the Brønsted acid centers located at the external crystal surface was invariant for the entire series. Ethanol conversion to ethyl-tert-butyl ether, proceeding only at the external surface, was also constant. The $\mathrm{OH}$ groups in MWW zeolites were found to be homogeneous with proton affinity value equal to $1142.7 \mathrm{~kJ} / \mathrm{mol}$.
\end{abstract}

Keywords MWW zeolites - ETBE synthesis - External surface acidity $\cdot$ IR and NMR studies

\section{Introduction}

The acidity of zeolites has been extensively studied over past decades [1-3]. As a result, more and more detailed knowledge about this complex phenomenon is being acquired, enabling not only better understanding of the properties of existing and functioning catalysts but also invention and tailoring the new ones. Real catalytic studies require not only the knowledge about the concentration of

B. Gil $(\bowtie) \cdot$ B. Marszałek

Faculty of Chemistry, Jagiellonian University, Ingardena 3, 30-060 Kraków, Poland

e-mail: gil@chemia.uj.edu.pl

\section{A. Micek-Ilnicka}

Institute of Catalysis and Surface Chemistry,

Niezapominajek 8, 30-239 Kraków, Poland

Z. Olejniczak

Institute of Nuclear Physics, Radzikowskiego 152,

31-342 Kraków, Poland acid sites but also on their relative strength, availability and type and to achieve this goal multiple probe molecules are employed [4, 5]. The acidity of the external surface of zeolites has gathered a lot of attention, mainly in the aspect of enhancing the shape selectivity of zeolites by passivating their external surface activity $[6,7]$.

The properties of zeolite MCM-22 [8] and its isomorphous structures ITQ-1 [9, 10], SSZ-25 [11], PSH-3 [12], and ERB-1 [13] have been thoroughly investigated for many years. MWW zeolites crystallize in the form of thin platelets with thickness in the range of just few framework layers. The layers contain two non-intersecting pore systems, both accessible through 10-rings only. One is a two-dimensional sinusoidal channel with uniform, 10-ring diameter $(4.1 \times 5.1 \AA)$ throughout the structure. The other is formed by the series of supercages of diameter equal to $7.1 \AA$ (12-rings) with unusually large inner height of $18.2 \AA$, accessible through the elliptic 10-ring openings $(4.0 \times 5.5 \AA)$.

One of the peculiarities of the MCM-22 zeolite is the fact that it can be formed via two different synthesis methods: either by calcination of the layered precursor MCM-22(P) or by a direct hydrothermal synthesis from a reaction gel. This property is slowly emerging as a more general trend for zeolites [14]. Another rarity presented by the MCM-22 is the unusually large ${ }^{29} \mathrm{Si}$ MAS-NMR shift range (ca. $15 \mathrm{ppm}$ ), pointing to large distribution of crystallographic environments present in this structure. Although both hexagonal and orthorhombic forms may be proposed for the MCM-22 zeolite [15, 16], the NMR data determined on highly-siliceous zeolites favor the orthorhombic one with 13 non-equivalent T-sites, one of them being 'buried' within the structure, not accessible from either channel systems [17]. The sitting of aluminum, both in the parent samples [18], and modified by dealumination or desilication [19] has also been investigated. 
MCM-22 (and MCM-49), in contrast to majority of other zeolites, contain hydroxyl groups located at the external surface of the zeolite crystals, namely inside the 12-ring pockets ('cups'). Such protons are responsible for the catalytic activity in hydrocarbons transformation, like alkylation of benzene with ethene and propene among others [20-22]. For that reason investigation of the specific location of acidic hydroxyl groups in the framework of the MWW-type zeolite is of vital importance.

According to literature [16, 23], the synthesis method may influence some of the properties of MWW zeolites, for that reason in the current work the MCM-22 zeolites originating from different laboratories as well as MCM-49 zeolite are investigated.

The goal of this work is to present the uniqueness of some of the features for series of the MWW zeolites, i.e. MCM-22 and MCM-49, differing in the Si/Al ratio. Discussion on the distribution of the framework $\mathrm{Al}$ atoms and thus acidic hydroxyl groups responsible for the catalytic activity of these zeolites is also presented. The novelty of this work is detailed characterization of the acid properties of the MWW zeolites (MCM-22 and MCM-49) including the quantification of the external acid sites and its comparison to the catalytic activity of the reaction catalyzed exclusively on the external acid sites.

\section{Experimental}

MCM-22 and MCM-49 samples were kindly provided by J. Čejka and B. Sulikowski (MCM-22/29 sample). Chemical composition of the zeolite samples was determined by X-ray fluorescence analysis using a spectrometer Philips PW 1404 provided with an analytical program UniQuant.

Solid state Magic-Angle-Spinning Nuclear Magnetic Resonance (MAS-NMR) spectra were acquired on the APOLLO console (Tecmag) at the magnetic field of $7.05 \mathrm{~T}$ (Magnex). For the ${ }^{29} \mathrm{Si}$ MAS-NMR spectra a $3 \mu$ s rf pulse ( $\pi / 2$ flipping angle) was used, $4 \mathrm{kHz}$ spinning speed, and 256 scans with the delay of $40 \mathrm{~s}$ were acquired. The ${ }^{27} \mathrm{Al}$ spectra were recorded using the $2 \mu$ s rf pulse ( $\pi / 6$ flipping angle), $8 \mathrm{kHz}$ spinning speed, and 1,000 scans with acquisition delay $1 \mathrm{~s}$.

The acidity was investigated by adsorption of $\mathrm{CO}$, pyridine and pivalonitrile used as probe molecules, followed by FTIR spectroscopy. All samples were activated in the form of self-supporting wafers (ca. $5 \mathrm{mg} \mathrm{cm}^{-2}$ ) at the conditions given below under vacuum prior to adsorption of the probe molecules. The adsorption temperatures were: carbon monoxide at $-100{ }^{\circ} \mathrm{C}$, pyridine at $170{ }^{\circ} \mathrm{C}$, and pivalonitrile at RT. Spectra were recorded on a Bruker Tensor 27 spectrometer, equipped with an MCT detector, working at $2 \mathrm{~cm}^{-1}$ resolution. All measured spectra were recalculated to a 'normalized' wafer of $10 \mathrm{mg}$ (density $3.2 \mathrm{~g} \mathrm{~cm}^{-2}$ ).

Samples are designated as MCM-22/n, where $n$ is the $\mathrm{Si} /$ Al ratio from the IR analysis. Textural properties of the studied samples were already presented elsewhere [24, 25].

Ethyl alcohol (p.p.a., 96\%, POCh Gliwice), isobutene (p.a., Aldrich), tert-butyl alcohol (Aldrich) and ethyl-tertbutyl ether (ETBE) (99\%, Aldrich) were used in the catalytic experiments. The test reaction of ETBE was carried out in a quartz constant flow differential microreactor $(\phi$ $=10 \mathrm{~mm}$ ). The helium carrier gas was first saturated with ethanol vapor and subsequently mixed with a stream of isobutene. The composition of the reaction mixture (isobutene/ethanol molar ratio) was equal to one. The catalytic reactor was connected on line with the Perkin-Elmer AutoSystem XL gas chromatograph and a Porapak QS column was used for the chromatographic analyses. Before catalytic experiments the ammonium forms of zeolites were activated ex situ at $500{ }^{\circ} \mathrm{C}$ to obtain the acidic forms. After that, the $0.1 \mathrm{~g}$ samples of selected zeolites were preheated at $200{ }^{\circ} \mathrm{C}$ for $30 \mathrm{~min}$ in situ in the catalytic reactor (in helium flow of $30 \mathrm{~mL} / \mathrm{min}$ ) to remove adsorbed water. Catalytic experiments were carried at $80^{\circ} \mathrm{C}$. Each measurement was repeated five times to obtain a representative average.

\section{Results and Discussion}

FTIR spectroscopy is a direct method of acidity measurement and offers only indirect evidence about the location of $\mathrm{Al}$ atoms, since not all aluminum atoms form acidic $\mathrm{Si}-$ $\mathrm{OH}-\mathrm{Al}$ groups. On the other hand, only those $\mathrm{Al}$ atoms which are in fact connected with acidic hydroxyls are interesting from the catalytic point of view [26, 27].

IR spectra in the region of $\mathrm{OH}$ vibrations were recorded at low temperature (ca. $-100{ }^{\circ} \mathrm{C}$ ) to allow for better apparent resolution (Fig. 1a). There are several bands of hydroxyl groups present in all zeolites under study. Three bands are characteristic of different silanol groups-terminal silanols at $3,750 \mathrm{~cm}^{-1}$, hydrogen-bonded silanols at $3,743 \mathrm{~cm}^{-1}$ and geminal silanols at $3,733 \mathrm{~cm}^{-1}$. The presence of the band at $3,733 \mathrm{~cm}^{-1}$ depends on the activation temperature. Condensation of the $3,733 \mathrm{~cm}^{-1}$ silanols leads to formation of isolated silanol groupsdecrease of the band at $3,733 \mathrm{~cm}^{-1}$ is accompanied by the intensity increase of the band at $3,750 \mathrm{~cm}^{-1}$ (Fig. 1b). In most of the studies reported in the literature, MWW-type zeolites are activated at quite high temperatures (usually well above $500{ }^{\circ} \mathrm{C}$ ) and therefore the band due to geminal silanols is absent in the majority of them. The band at $3,670 \mathrm{~cm}^{-1}$ present in MCM-49 alone is characteristic of extraframework $\mathrm{Al}$ species containing its own $\mathrm{OH}$ groups; 
Fig. 1 IR spectra in the region of $\mathrm{OH}$ vibration (all spectra normalized to $10 \mathrm{mg}$ pellet). a MWW zeolites activated at $500{ }^{\circ} \mathrm{C}$ : MCM-49 (a), MCM22/10 (b), MCM-22/21(c), MCM-22/29 (d) and MCM-22/ 40 (e). b MCM-22/29 activated at increasing temperatures: from top to bottom $100-700{ }^{\circ} \mathrm{C}$ (with $100{ }^{\circ} \mathrm{C}$ interval)
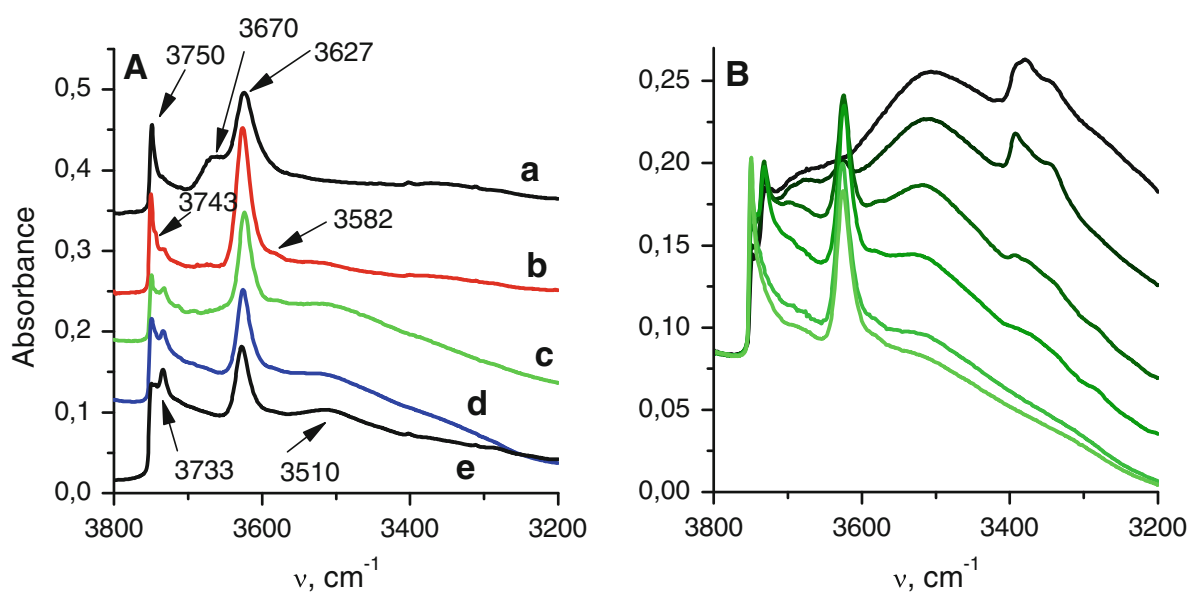

this band is absent from other zeolites. Such a band is usually present in high silica zeolites at the lowest region of $\mathrm{Si} / \mathrm{Al}$ or ultrastabilized zeolites [28]. Usually, the presence of such extraframework $\mathrm{Al}$ atoms is not connected with the occurrence of the $0 \mathrm{ppm}$ signal in the ${ }^{27} \mathrm{Al}$ MAS-NMR spectrum [29] because such species cannot form symmetric $\left[\mathrm{Al}\left(\mathrm{H}_{2} \mathrm{O}\right)_{6}\right]^{3+}$ complexes due to the presence of strongly bonded $\mathrm{OH}$ group. Moreover, some of these aluminumcontaining species reveal the Brønsted-type acidity. In the region of the acidic $\mathrm{Si}-\mathrm{OH}-\mathrm{Al}$ groups two bands can be easily distinguished-at $3,627 \mathrm{~cm}^{-1}$ of acidic hydroxyls in 12-ring and 10-ring channels and $3,582 \mathrm{~cm}^{-1}$ of $\mathrm{OH}$ groups located in hexagonal prisms in between supercages [30]. The amount of $\mathrm{OH}$ groups in hexagonal prisms seems to be constant in all MCM-22 zeolites while this band is practically absent in MCM-49, which is the sample with the highest $\mathrm{Al}$ content $(\mathrm{Si} / \mathrm{Al}=12)$. At the lowest presented region the band at $3,510 \mathrm{~cm}^{-1}$ can be observed, assigned to silanol nests. Their presence is indicative of the framework disorder and for this series, as anticipated, is increasing with the increased amount of $\mathrm{Al}$ although in none of the cases the intensity of this band is significant.

One of the basic features of zeolites is the ratio between framework $\mathrm{Si}$ and $\mathrm{Al}$ atoms, which quantitatively characterizes acidity of each sample. To measure the total concentration of acidic species, the experiments of pyridine adsorption was performed. Since MCM-22 (and MCM-49) are very unique zeolites, as the first step the experiments determining the value of the absorption coefficient of pyridinium ions $\left(\mathrm{PyH}^{+}\right.$at $\left.1,545 \mathrm{~cm}^{-1}\right)$ was made. Pyridine was adsorbed in MCM-22/10 containing only small amount of extraframework Lewis sites, which were saturated during the adsorption of the first pyridine dose. This spectrum was consequently not used for the calculation of the absorption coefficient, according to the procedure described in details in one of our previous publications [31]. The value of the $\mathrm{PyH}^{+} 1,545 \mathrm{~cm}^{-1}$ band absorption coefficient determined in that experiment was equal to $0.044 \mathrm{~cm} /$ $\mu$ mol. The absorption coefficient for pyridine bonded to Lewis sites was taken from our earlier work [32]. On the basis of these values and the intensity of the proper IR bands after pyridine adsorption and subsequent evacuation at $250{ }^{\circ} \mathrm{C}$ the $\mathrm{Si} / \mathrm{Al}$ ratio and the number of Lewis sites for all samples were calculated. The high desorption temperature was chosen because of very strong interaction between silanol groups and pyridine. The band of pyridine bonded to $\mathrm{SiOH}$ groups at $1,445 \mathrm{~cm}^{-1}$ in most cases vanished only after desorption at $250{ }^{\circ} \mathrm{C}$, therefore the intensity of the $1,455 \mathrm{~cm}^{-1}$ band of pyridine coordinated to the Lewis sites could be determined with better accuracy. All $\mathrm{Si} / \mathrm{Al}$ values determined on this basis are close to the ones derived from the XRF analysis of non-calcined samples. This shows that two steps of the thermal treatment-calcination in order to remove template and further activation transforming ammonium form of the zeolite into protonic one (both at $500{ }^{\circ} \mathrm{C}$ ) are not causing significant dealumination of the samples, which will be further confirmed by the ${ }^{29} \mathrm{Al}$ MAS-NMR. The number of Lewis acid sites for all MCM-22 samples was around 7\% and for MCM-49 ca. $10 \%$ of all acidic centers present. What is interesting, in the MCM-49 zeolite the part of the band due to extraframework aluminum at $3,670 \mathrm{~cm}^{-1}$ is disappearing after pyridine adsorption, as showed in Fig. 2. This means that there are two types of extraframework aluminum species in MCM-49-one displaying Brønsted acidity (band at $3,654 \mathrm{~cm}^{-1}$ ) and the other, at $3,668 \mathrm{~cm}^{-1}$, non-acidic. The latter band is slightly blue-shifted after pyridine adsorption, which is sometimes observed during pyridine adsorption [33]. For all zeolites the $\mathrm{OH}$ groups in hexagonal prisms (band at 3,582 $\mathrm{cm}^{-1}$ ) are interacting with pyridine because even if pyridine is not able to enter hexagonal prisms, it is able to withdrawn protons from their original positions [5]. During thermodesorption this band is not restored after pyridine desorption at $520{ }^{\circ} \mathrm{C}$ (spectra not shown). This 


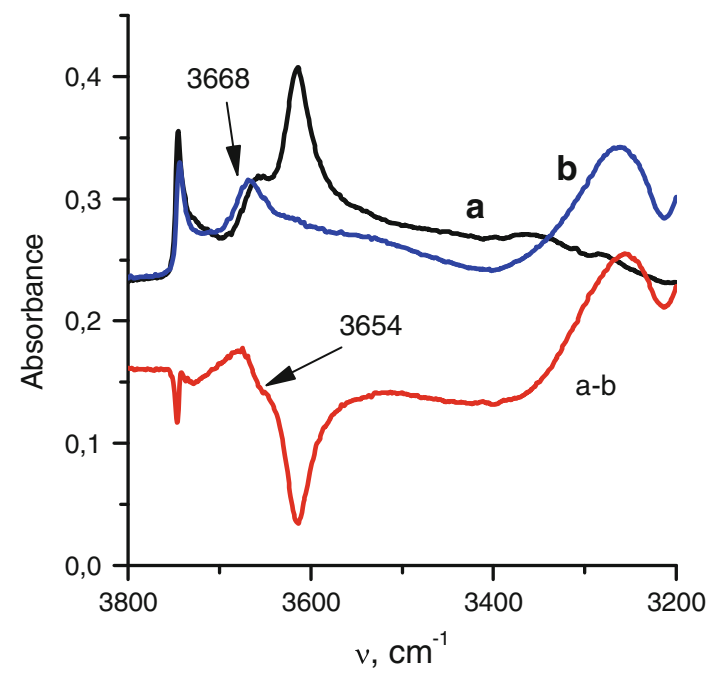

Fig. 2 Spectra of the $\mathrm{OH}$ groups in zeolite MCM-49 during pyridine adsorption. $a$ spectrum of activated zeolite, $b$ after pyridine adsorption and desorption at $250{ }^{\circ} \mathrm{C},(a-b)$ difference spectrum. All spectra at $170{ }^{\circ} \mathrm{C}$

could serve as the additional evidence that such $\mathrm{OH}$ groups are indeed located in the environment from which the desorption of pyridine is difficult.

For most of the zeolites, the $\mathrm{Si} / \mathrm{Al}$ ratio determined on the basis of the ${ }^{29} \mathrm{Si}$ MAS-NMR and IR spectroscopy match very well. In the case of MCM-22 zeolites, however, chemical shift of the $\mathrm{Si}$ signals depends strongly on the geometric environment of each Si site (Fig. 3). The signal at $-100 \mathrm{ppm}$ is the superposition of two components: $\mathrm{Si}(3 \mathrm{Si}) \mathrm{OH}$ and $\mathrm{Si}(1 \mathrm{Al}) \mathrm{OH}$, both associated with the presence of a silicon atom connected with a single $\mathrm{OH}$ group. Although the fitted signal at $-100 \mathrm{ppm}$ is wider for the samples with lower Si/Al ratio (Fig. 4) further deconvolution of this signal would be ambiguous. The intensity change of the $-100 \mathrm{ppm}$ signal is not monotonic with $\mathrm{Si} /$ $\mathrm{Al}$ because the intensity decrease caused by decreasing $\mathrm{Al}$ amount is accompanied by change in the $\mathrm{SiOH}$ groups concentration (Fig. 1a).

In MCM-22 zeolites, the ${ }^{27} \mathrm{Al}$ NMR signal due to tetrahedral $\mathrm{Al}$ clearly consists of two components: at 55 and $48 \mathrm{ppm}$ (Fig. 5). It is worth to note that the ratio between 55 and $48 \mathrm{ppm}$ signals is changing - the higher the amount of $\mathrm{Al}$ (lower $\mathrm{Si} / \mathrm{Al}$ ), the more intense is the $55 \mathrm{ppm}$ signal compared to the $48 \mathrm{ppm}$ one. Since Al atoms may be located in two distinct pore systems proposed for this zeolite, the presence of the two sets of signals derived from tetrahedral $\mathrm{Al}$ is understandable [34]. Lippmaa et al. [35] showed that the chemical shifts of tetrahedral Al correlate with average $\mathrm{Al}-\mathrm{O}-\mathrm{Si}$ angles in zeolite frameworks and on this basis the average angles of $152^{\circ}$ and $164^{\circ}$ for the 55 and $48 \mathrm{ppm}$ components were assigned. Keneddy et al. [17] then assigned the presence of the $55 \mathrm{ppm}$ peak to the

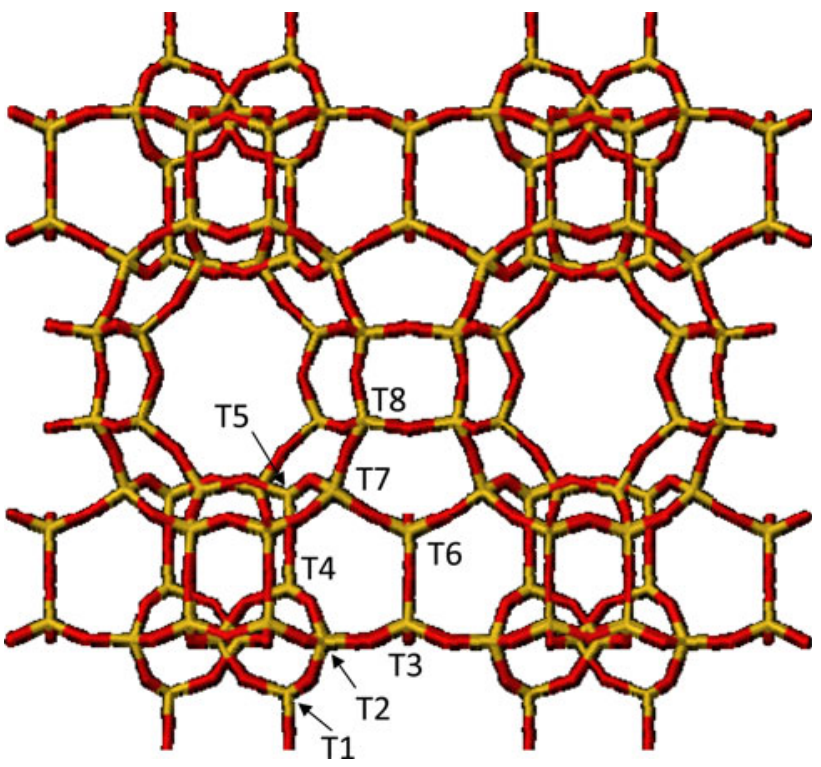

Fig. 3 Schematic illustration of one layer of MCM-22 showing nonequivalent $\mathrm{Td}$ positions

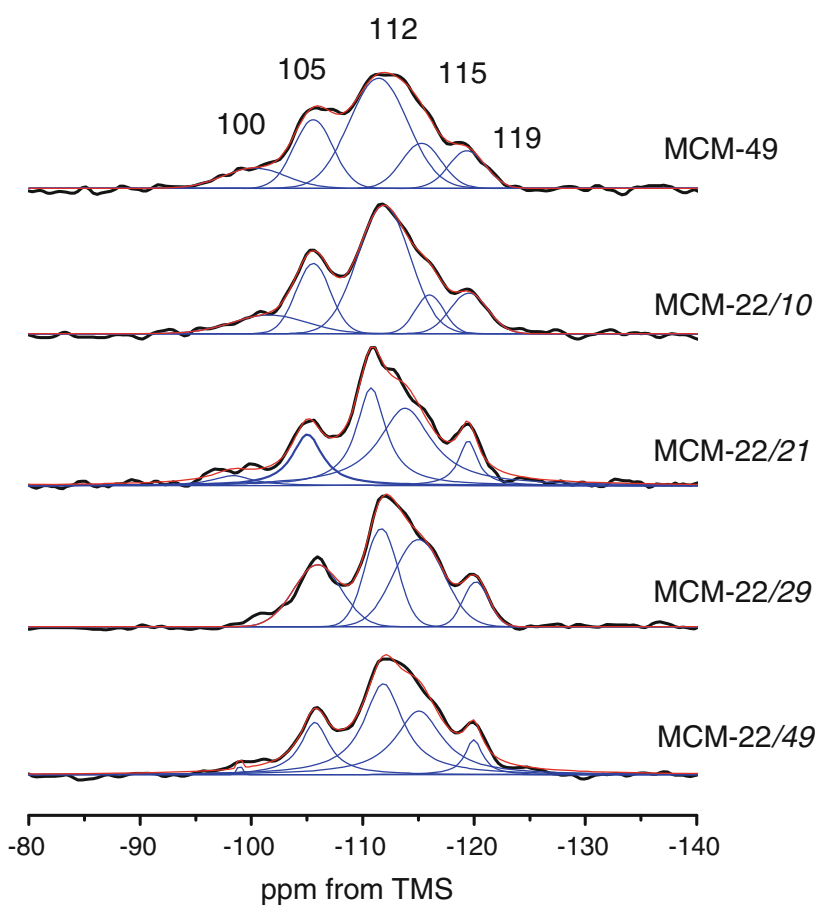

Fig. $4{ }^{29}$ Si MAS-NMR spectra of the MWW zeolites

population of $\mathrm{T} 1, \mathrm{~T} 3, \mathrm{~T} 4, \mathrm{~T} 5, \mathrm{~T} 8$ sites and the $48 \mathrm{ppm}$ peak to $\mathrm{T} 6$ and $\mathrm{T} 7$ sites. In this particular case the increase of the $\mathrm{Al}(\mathrm{Td})$ signal at $55 \mathrm{ppm}$ can be interpreted by $\mathrm{Al}$-enrichment of the T1, T3, T4, T5, T8 sites relative to the T6, T7 sites. The low number of Lewis acid centers detected by pyridine is consistent with low intensity of the $0 \mathrm{ppm}$ signal due to extraframework $\mathrm{Al}$. 

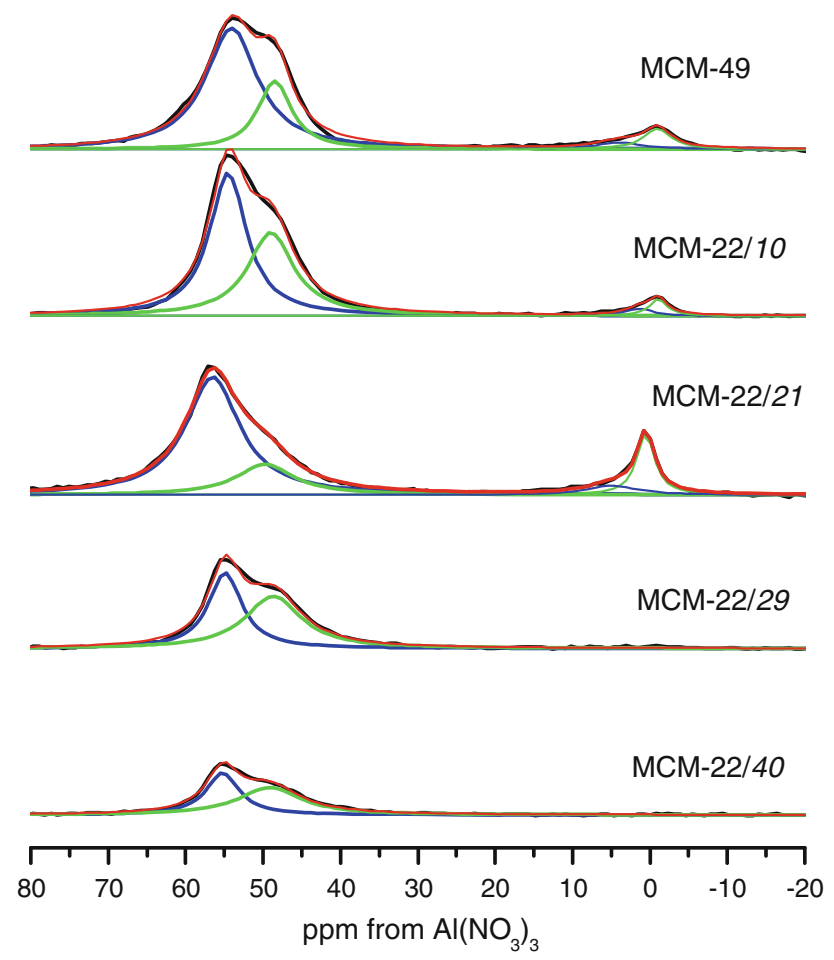

Fig. $5{ }^{27} \mathrm{Al}$ NMR spectra of MWW zeolites

Pyridine is unable to recognize the type of Lewis acid centers-whether they are intrinsic Lewis sites, originating from the defective aluminum atoms (placed outside the framework already during synthesis) or Lewis sites arising from dehydroxylation. The type of Lewis acid centers present was therefore determined by adsorption of CO. All MWW-type zeolite samples were activated at increasing temperatures: 100 to $700{ }^{\circ} \mathrm{C}$, and after each activation step $\mathrm{CO}$ was adsorbed at $-100{ }^{\circ} \mathrm{C}$. Figure 6 shows the spectra of $\mathrm{CO}$ adsorption in two zeolites of similar $\mathrm{Si} / \mathrm{Al}$ ratio: MCM-22/10 and MCM-49 with higher amount of extraframework Al. At low activation temperatures (up to $400{ }^{\circ} \mathrm{C}$ ) in neither zeolite the bands due to $\mathrm{CO}$ bonded to Lewis acid sites are present, at the same time those centres cannot be saturated by molecular water because the bands of $\mathrm{H}-\mathrm{O}-\mathrm{H}$ bending vibrations are absent in the spectra recorded even after activation at $100{ }^{\circ} \mathrm{C}$. At higher temperatures two bands appear: the one at $2,240 \mathrm{~cm}^{-1}$ is characteristic for Lewis sites resulting from dehydroxylation in all zeolites independent of their topology. The other, at 2,228 $\mathrm{cm}^{-1}$, appears only as a result of dehydroxylation of a MWW structure [36]. The latter band appears first and later on both bands increase their intensities simultaneously. Careful analysis of the difference spectra suggests that the $\mathrm{OH}$ groups from 12- and 10-ring channels dehydroxylate first while the band characteristic of $\mathrm{OH}$ groups from hexagonal prisms did not decrease its intensity. In neither zeolite the bands of $\mathrm{CO}$ bonded to intrinsic Lewis sites $\left(2,190 \mathrm{~cm}^{-1}\right)$ are present indicating that all the framework defects are caused by temperature treatment.

\section{Strength of the Acid Sites}

Acid strength of the $\mathrm{Si}-\mathrm{OH}-\mathrm{Al}$ groups can be estimated in two independent experiments: pyridine thermodesorption and $\mathrm{CO}$ adsorption. In the first case the determinant of the acid strength is the amount of pyridine present in zeolite after selected desorption temperature. Such experiment is in fact dependent on two factors: the intrinsic acid strength of the given $\mathrm{OH}$ group and diffusivity limits. In the latter case, the determinant of the acid strength of a given $\mathrm{OH}$ group is the value of the red-shift of its IR band, caused by its interaction with the $\mathrm{CO}$ molecule. The $\mathrm{CO}$ adsorption is a static experiment, independent of diffusion.

During $\mathrm{CO}$ adsorption all $\mathrm{OH}$ groups interact with the introduced probe molecule (Fig. 7). The red-shift of the acidic $\mathrm{Si}-\mathrm{OH}-\mathrm{Al}$ groups was the same for all MWW samples, equal to $326 \mathrm{~cm}^{-1}$. On the basis of this red-shift, proton affinity (PA) can be calculated using the modified [37] Paukshtis and Yurchenko equation [38]: $\mathrm{PA}=\mathrm{PA}_{\mathrm{st}}$ $-442.5 \log (\Delta v)$. The value of $1142.7 \mathrm{~kJ} / \mathrm{mol}$ was determined, which is comparable to the one for LZY-82, ultrastabilized zeolite $\mathrm{Y}\left(\Delta v=315 \mathrm{~cm}^{-1}, \mathrm{PA}=1149.5 \mathrm{~kJ} /\right.$ mol), much lower than for ZSM-5 $\left(\Delta v=310 \mathrm{~cm}^{-1}, \mathrm{PA}=\right.$ $1152.4 \mathrm{~kJ} / \mathrm{mol})$ or ferrierite $\left(\Delta v=293 \mathrm{~cm}^{-1}, \mathrm{PA}=1163.2\right.$ $\mathrm{kJ} / \mathrm{mol}$ ) indicating much higher acid strength of $\mathrm{Si}-\mathrm{OH}-\mathrm{Al}$ groups in MWW-type zeolites, irrespective of their $\mathrm{Si} / \mathrm{Al}$ ratio or synthesis method. On the basis of $\mathrm{CO}$ adsorption it is impossible to determine the red-shift of $\mathrm{OH}$ groups located in hexagonal prisms (the band at $3,582 \mathrm{~cm}^{-1}$ ). Even very careful analysis of the subtraction spectra is not revealing any additional red-shifted components suggesting that all types of $\mathrm{Si}-\mathrm{OH}-\mathrm{Al}$ groups have the same acid strength. The dependence between the half-width of the IR bands of the hydrogen-bonded $\mathrm{OH}$ groups $\left(\Delta v_{1 / 2}\right)$ on the value of this redshift $(\Delta v)$ can be also used to determine heterogeneity of the acid centers. For that purpose the method of investigation of the heterogeneity of $\mathrm{Si}-\mathrm{OH}-\mathrm{Al}$ groups in zeolites taken from our previous work [39] is applied. Figure $7 \mathrm{~b}$ shows the line being the upper limit of the dependence of $\Delta v\left(\Delta v_{1 / 2}\right)$ for the compounds containing homogeneous $\mathrm{OH}$ groups (zeolite A, dealuminated Beta and NaHX among others). The point for all MWW materials from the current work is located below the line which is the evidence of homogeneity of the acid strength of the $\mathrm{Si}-\mathrm{OH}-\mathrm{Al}$ groups in all of the investigated samples.

The pyridine thermodesorption experiment points to differences of acid strength among the investigated zeolites (Table 1) the result which is in contradiction to the results of $\mathrm{CO}$ adsorption. The values of $\mathrm{A}_{520} / \mathrm{A}_{250}$, where $\mathrm{A}_{520}$ is 
Fig. 6 Spectra of $\mathrm{CO}$ adsorbed on MCM-49 (a) and MCM-22/ 10 (b) activated at increasing temperatures. From bottom to top $300,400,500,600$, and $700{ }^{\circ} \mathrm{C}$. All spectra normalized to $10 \mathrm{mg}$ pellet
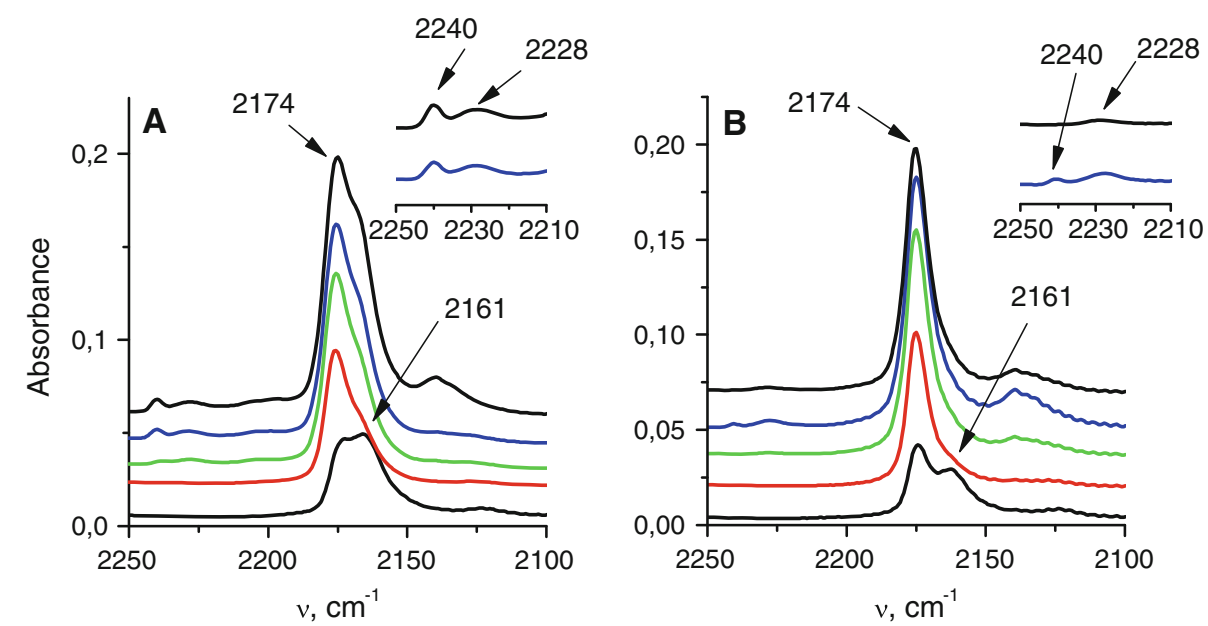

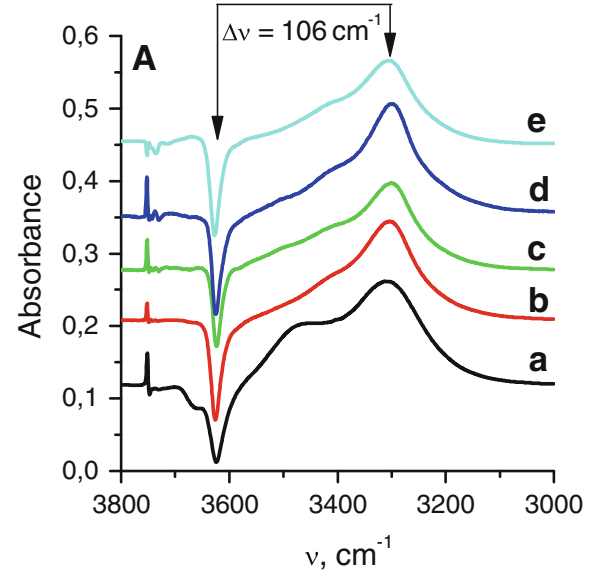

Fig. 7 a IR spectra of $\mathrm{OH}$ groups interacting with $\mathrm{CO}$ in MWW zeolites activated at $500{ }^{\circ} \mathrm{C}$ : MCM-49 (a), MCM-22/10 (b), MCM22/21 (c), MCM-22/29 (d) and MCM-22/40 (e). Background spectra of activated samples were subtracted. b line showing the dependence

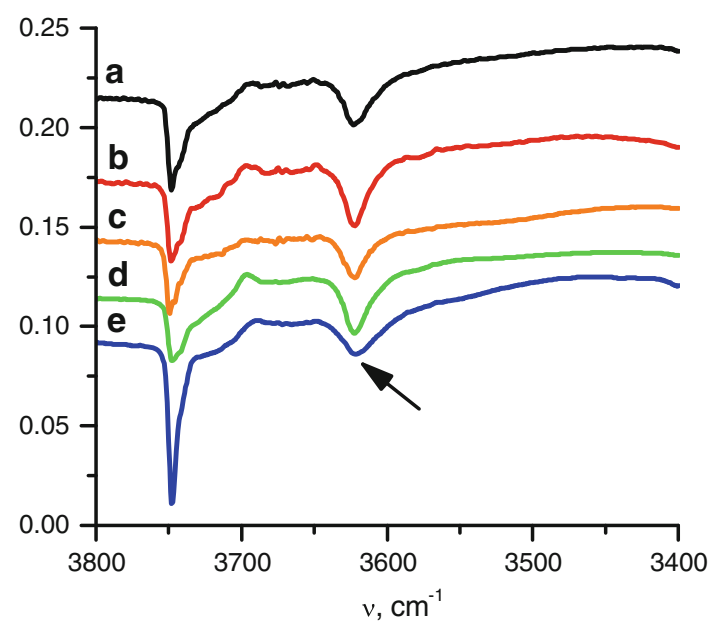

Fig. 8 IR spectra of $\mathrm{OH}$ groups interacting with pivalonitrile in MWW zeolites activated at $500{ }^{\circ} \mathrm{C}$ : MCM-49 (a), MCM-22/10 (b), MCM-22/21 (c), MCM-22/29 (d) and MCM-22/40 (e). Background spectra of activated samples were subtracted

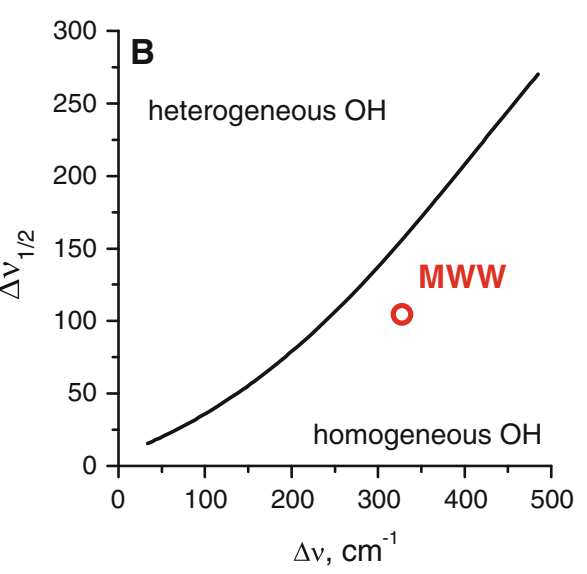

of the $\Delta v_{1 / 2}$ (half-width of the red-shifted band of $\mathrm{OH}$ groups) on $\Delta v$ (the value of the red-shift caused by $\mathrm{CO}$ adsorption) for homogeneous $\mathrm{OH}$ groups (from [26]) and the point for investigated MWW zeolites

the intensity of the pyridinium ion band at $1,545 \mathrm{~cm}^{-1}$ after desorption at $520{ }^{\circ} \mathrm{C}$ and $\mathrm{A}_{250}$ is the maximum intensity of this band (after desorption at $250{ }^{\circ} \mathrm{C}$ ) is taken as the direct measure of the acid strength of $\mathrm{OH}$ groups in MWW zeolites. Higher values of $\mathrm{A}_{520} / \mathrm{A}_{250}$ point to higher acid strength of the acidic centers. In this method of acidity measurement, the acid strength is in fact related not only to the "intrinsic" acid strength of the $\mathrm{OH}$ groups but also to some extent to the diffusion limitation-especially when the channel dimensions in the given zeolite structure are similar to the kinetic diameter of the probe molecule used during the test. In the case of MWW zeolites, the dimensions of 10-rings channels $(4.0 \times 5.5$ and $4.1 \times 5.1 \AA)$ are similar to pyridine kinetic diameter $(5 \AA)$ therefore the diffusion limitation may influence the measurement of the acid strength. The values $\mathrm{A}_{520} / \mathrm{A}_{250}$ are indicating the acidity order: MCM-22/40 > MCM-49 > MCM-22/ $10>\mathrm{MCM}-22 / 21>\mathrm{MCM}-22 / 29$. This order is following 
Table 1 Physicochemical characterization of the MWW samples

\begin{tabular}{|c|c|c|c|c|c|c|c|}
\hline Sample & $\operatorname{BET}\left(\mathrm{m}^{2} / \mathrm{g}\right)$ & $\mathrm{Si} / \mathrm{Al}$ (XRF) & Si/Al (IR) & $\mathrm{Al}_{\text {fram }} / \mathrm{Al} 1_{\text {extraf }}$ & $\mathrm{C}_{\mathrm{BAS}} / \mathrm{C}_{\mathrm{LAS}}$ & $\mathrm{A}_{520} / \mathrm{A}_{250}$ & External $\mathrm{OH} /$ u.c. \\
\hline МCM-49 & 490 & 8 & 12 & 10.4 & 9.1 & 0.53 & 0.22 \\
\hline MCM-22/10 & 542 & 14 & 10 & 21.2 & 12.1 & 0.43 & 0.36 \\
\hline MCM-22/21 & 418 & 33 & 21 & 2.1 & 13.7 & 0.36 & 0.22 \\
\hline MCM-22/29 & 481 & 31 & 29 & $-^{\mathrm{a}}$ & 13.1 & 0.25 & 0.28 \\
\hline MCM-22/40 & 329 & 42 & 40 & $-^{\mathrm{a}}$ & 12.6 & 0.46 & 0.28 \\
\hline
\end{tabular}

a Intensity of the $0 \mathrm{ppm}$ band is below detection limit

the $\mathrm{Si} / \mathrm{Al}$ ratio increase with the exception of the MCM-22/ 40 sample. In the latter case however, it can be supposed that crystallites may form small aggregates, effectively elongating the diffusion path. It is worth mentioning that even for the MCM-49 sample, which has the highest aluminum content, all acidic $\mathrm{Si}-\mathrm{OH}-\mathrm{Al}$ may be considered as isolated, therefore all of them should display uniform and high acid strength as it was proven by the experiment of $\mathrm{CO}$ adsorption. The apparent different acid strengths for the series of MWW-type zeolites is most probably due to diffusion limitations, which is most likely caused by pyridine readsorption on the neighboring acid centers as it migrates along the channel. Channel exits are located on the side walls of MWW crystals, which means that a desorbing molecule has to diffuse along the whole crystal, thus the probability that it will encounter and readsorb on the subsequent acid centers depends on the concentration of the acid sites and should diminish with the increasing Si/Al. Such trend was also observed with other measurement methods [40, 41].

\section{Pivalonitrile Sorption: Studies of the Accessibility of Si-OH-Al Groups}

One of the most interesting features of MWW zeolites is the presence of acidic $\mathrm{OH}$ groups on the external surface of the crystals. This imparts a particular type of catalytic activity, which has been successful for application in the industry and MCM-22 is commercially used as the catalyst for ethylbenzene synthesis and cumene [42]. To study accessibility of the $\mathrm{OH}$ groups located inside these external 'cups' pivalonitrile adsorption was performed. Application of pivalonitrile as a probe molecule for testing external acidity of zeolites was proven useful by the group of Busca and co-workers [43]. The presence of tert-butyl group prevents entrance into the 10-ring openings and therefore restricting any interaction to the external surface of the MWW-type zeolites. Pivalonitrile is interacting only with fraction of the $\mathrm{OH}$ groups-those located at the external 'cups' or very nearly the pore entrances while is not interacting with the $\mathrm{OH}$ groups located in the hexagonal prisms in between the supercages (the difference band is not containing the submaximum at $3,582 \mathrm{~cm}^{-1}$ ). First, pivalonitrile was adsorbed at RT and afterwards its excess desorbed for $5 \mathrm{~min}$ at high vacuum $\left(\sim 10^{-4} \mathrm{mBa}\right)$. Then, from the intensity of the $3,621 \mathrm{~cm}^{-1}$ band consumed by pivalonitrile (Fig. 8) and its integrated absorption coefficient calculated by Ayrault et al. [44] and equal $2.5 \mathrm{~cm} /$ $\mu \mathrm{mol}$, the concentration of the external acidic $\mathrm{OH}$ groups was calculated. As can be seen from the data presented in Table 1, the number of external $\mathrm{OH}$ groups is basically independent of the $\mathrm{Si} / \mathrm{Al}$ ratio, sample origin and the synthesis method. This would suggest that, at least for the series investigated in the current work, any reaction occurring exclusively at the external zeolite surface should occur with very similar selectivity and yield.

\section{ETBE Synthesis}

As the test reaction the synthesis of ETBE from the equimolar mixture of ethanol and isobutene was chosen.<smiles>C=C(C)C[13CH2]C=C=CC(C)(C)OCC</smiles>

Because of the presence of the tert-butyl group even if such ether could have been formed inside the MWW supercage (both ethanol and isobutene can easily penetrate MWW micropores), its diffusion out of the zeolite channel system through the 10-ring openings would be impossible. Any ETBE molecule detected by the chromatography must have been therefore formed in the 'cups' at the external surfaces of the crystals. Reaction was performed at $80{ }^{\circ} \mathrm{C}$ because of too low yield at $60{ }^{\circ} \mathrm{C}(\mathrm{ca} .3 \%)$ while at $100{ }^{\circ} \mathrm{C}$ ETBE decomposition would occur. Two products of ethanol and isobutene reaction were present: ETBE and tertbutyl alcohol (product of the side reaction $\mathrm{C}_{4} \mathrm{H}_{8}+\mathrm{H}_{2} \mathrm{O}=$ $\left(\mathrm{CH}_{3}\right)_{3} \mathrm{COH}$, with the remaining water from ethanol); the latter with yield below $0.6 \%$ and formed also on the external zeolite surface. For the catalytic reaction only three samples, with different $\mathrm{Si} / \mathrm{Al}$ ratio and the method of 
Table 2 Catalytic performance of selected samples in ETBE synthesis from ethanol and isobutene at equimolar ratio (average from five measurements)

\begin{tabular}{llll}
\hline Sample & $\begin{array}{l}\text { EtOH conversion } \\
\text { to ETBE }(\%)\end{array}$ & $\begin{array}{l}\text { Yield of } \\
\text { ETBE }(\%)\end{array}$ & $\begin{array}{l}\text { Yield of } \\
\text { TBA }(\%)\end{array}$ \\
\hline MCM-49 & $10.0 \pm 0.89$ & $3.91 \pm 0.11$ & $0.56 \pm 0.015$ \\
MCM-22/21 & $9.51 \pm 1.03$ & $3.91 \pm 0.13$ & $0.57 \pm 0.063$ \\
MCM-22/29 & $9.79 \pm 1.46$ & $3.52 \pm 0.42$ & $0.56 \pm 0.047$ \\
\hline
\end{tabular}

synthesis were chosen. In all cases ethanol conversion to ETBE was virtually constant, as was the yield (Table 2).

As it was shown that ETBE synthesis was conducted exclusively at the external zeolite surface the fact that ether yield was constant corroborates the hypothesis that the concentration of the active centers at the external 'cups' was constant for all samples.

\section{Conclusions}

A series of MWW-type zeolites: MCM-22 samples with increasing $\mathrm{Si} / \mathrm{Al}$ ratio and an MCM-49 zeolite were investigated with respect to their acidic properties. The total concentration of Brønsted acid centers derived from the pyridine adsorption experiment followed by IR spectroscopy matched very well the $\mathrm{Si} / \mathrm{Al}$ ratio determined by the XRF.

Two types of the framework as well as extraframework aluminum was confirmed by ${ }^{27} \mathrm{Al}$ MAS-NMR. The ratio between the 48 and the $55 \mathrm{ppm}$ signals changed with the $\mathrm{Si} / \mathrm{Al}$ ratio. This can be interpreted by Al-enrichment of the T1, T3, T4, T5, T8 sites compared to the T6, T7 sites with increasing $\mathrm{Al}$ content.

OH groups in MWW zeolites were found to be homogeneous, with low PA value (high acid strength) equal to $1142.7 \mathrm{~kJ} / \mathrm{mol}$, which is comparable to the one for steamed HY zeolite and lower than in ZSM-5. Diffusivity was found to be very important determinant of the activity (in the terms of the apparent acid strength).

Concentration of Brønsted acid centers located on the external crystal surface was invariant for the entire series. This fact was further confirmed in the test reaction of ETBE synthesis from ethanol and isobutene which could be occur only at the external crystal surfaces and not inside due to sterical restrictions. Ethanol conversion to ETBE as well as the ether yield was constant.

Acknowledgments The research was carried out with the equipment purchased thanks to the financial support of the European Regional Development Fund in the framework of the Polish Innovation Economy Operational Program (Contract no. POIG.02.01.0012-023/08). IR measurements were made in the frames of the grant from the Ministry of Science and Higher Education, Warsaw (Project no. NN204 1987 33).
Open Access This article is distributed under the terms of the Creative Commons Attribution Noncommercial License which permits any noncommercial use, distribution, and reproduction in any medium, provided the original author(s) and source are credited.

\section{References}

1. Auroux A (2002) Top Catal 19:205

2. Čejka J, Wichterlová B (2002) Catal Rev 44:375

3. Corma A (1995) Chem Rev 95:559

4. Gil B, Zones SI, Hwang S-J, Bejblová M, Čejka J (2008) J Phys Chem C 112:2997

5. Lercher JA, Gründling C, Eder-Mirth G (1996) Catal Today 27:353

6. Wichterlová B, Čejka J (1992) Catal Lett 16:421

7. Weber RW, Möller KP, O’Connor CT (2000) Micropor Mesopor Mater 35:533

8. Leonowicz ME, Lawton JA, Lawton SL, Rubin MK (1994) Science 264:1910

9. Camblor MA, Corell C, Corma A, Diaz-Cabanas M-J, Nicolopoulos S, Gonzalez-Calbet JM, Vallet-Regi M (1996) Chem Mater $8: 2415$

10. Camblor MA, Corma A, Diaz-Cabanas M-J, Baerlocher Ch (1998) J Phys Chem B 102:44

11. Zones SI, Hwang SJ, Davis ME (2001) Chem Eur J 7:1990

12. Puppe L, Weisser J (1984) US Patent 4,439,409

13. Belussi G, Perego G, Clerici MG, Giusti A (1988) European Patent Application, EPA 293032

14. Roth WJ (2007) Stud Surf Sci Catal 168:221

15. Kennedy GJ, Lawton SL, Fung AS, Rubin MK, Steuernagel S (1999) Catal Today 49:385

16. Aiello R, Crea F, Testa F, Demortier G, Lentz P, Wiame M, Nagy JB (2000) Micorpor Mesopor Mater 35-36:585

17. Kennedy GJ, Lawton SL, Rubin MK (1994) J Am Chem Soc 116:11000

18. Dědeček J, Čejka J, Oberlinger M, Ernst S (2002) Stud Surf Sci Catal 142 A:23

19. Van Miltenburg A, Pawlesa J, Bouzga AM, Žilková N, Čejka J, Stöcker M (2009) Top Catal 52:1190

20. Degnan TF Jr, Morris Smith C, Venkat CR (2001) Appl Catal A 221:283

21. Park S-H, Rhee H-K (2000) Catal Today 63:267

22. Čejka J, Krejci A, Zilkova N, Kotrla J, Ernst S, Weber A (2002) Micropor Mesopor Mater 53:121

23. Delitala C, Alba MD, Becerro AI, Delpiano D, Meloni D, Musu E, Ferino I (2009) Micropor Mesopor Mater 118:1

24. Pawlesa J, Zukal A, Čejka J (2007) Adsorption 13:257

25. Mokrzycki Ł, Sulikowski B, Olejniczak Z (2009) Catal Lett 127:296

26. Rhodes CJ (2008) Prog React Kinet Mech 33:1

27. Katada N, Niwa M (2004) Catal Surv Asia 8:161

28. Datka J, Sulikowski B, Gil B (1996) J Phys Chem 100:11242

29. Engelhardt G, Lohse U, Patzelova V, Mägi M, Lippmaa H (1983) Zeolites 3:233

30. Onida B, Geobaldo F, Testa F, Aiello R, Garrone E (2002) J Phys Chem B 106:1684

31. Thibault-Starzyk F, Gil B, Aiello S, Chevreau T, Gilson J-P (2004) Micropor Mesopor Mater 67:107

32. Datka J, Gil B, Kubacka A (1996) Zeolites 17:428

33. Makarova MA, Karim K, Dwyer J (1995) Micropor Mater 4:243

34. Kolodziejski W, Zicovich-Wilson C, Corell C, Perez-Pariente J, Corma A (1995) J Phys Chem 99:7002 
35. Lippmaa E, Samoson A, Mägi M (1986) J Am Chem Soc 108:1730

36. Góra-Marek K, Datka J (2005) Stud Surf Sci Catal 158A:83

37. Datka J, Broclawik E, Gil B (1994) J Phys Chem $98: 5622$

38. Paukshtis EA, Yurchenko EN (1983) Usp Khim 52:426

39. Datka J, Gil B (2001) Catal Today 70:131

40. Meloni D, Laforge S, Martin D, Guisnet M, Rombi E, Solinas V (2001) Appl Catal A 215:55
41. Okumura K, Hashimoto M, Mimura T, Niwa M (2002) J Catal 206:23

42. Corma A, Martínez-Soria V, Schnoeveld E (2000) J Catal 192:16

43. Bevilacqua M, Meloni D, Sini F, Monaci R, Montanari T, Busca G (2008) J Phys Chem C 112:9023

44. Ayrault P, Datka J, Laforge S, Martin D, Guisnet M (2004) J Phys Chem B 108:13755 